\title{
A Disposable Single-Use Electrochemical Sensor for Detection of Resorcinol Based on Electrochemically Activated Screen Printed Carbon Electrode in Hair Dyes
}

\author{
Periyalagan Alagarsamy ${ }^{1}$, G. Navaneetha Krishnan ${ }^{2}$, Shen-Ming Chen ${ }^{3 *}$, Thangavelu Kokulnathan ${ }^{3}$, \\ Tse-Wei Chen ${ }^{3}$, Nehru Raja ${ }^{3}$, Xiaoheng Liu ${ }^{4 *}$, In-Seok Hong ${ }^{1}$, V. Selvam ${ }^{5}$ \\ ${ }^{1}$ Department of Chemistry, College of Natural Science, Kongju National University, Republic of \\ Korea. \\ ${ }^{2}$ Department of Mechanical Engineering, K. Ramakrishnan College of Technology, Trichy, India. \\ ${ }^{3}$ Electroanalysis and Bioelectrochemistry Lab, Department of Chemical Engineering and \\ Biotechnology, National Taipei University of Technology, No.1, Section 3, Chung-Hsiao East Road, \\ Taipei 106, Taiwan (R.O.C). \\ ${ }^{4}$ Key Laboratory of Education Ministry for Soft Chemistry and Functional Materials, Nanjing \\ University of Science and Technology, Nanjing 210094, China. \\ ${ }^{5}$ Department of Chemistry, V.H.N.S.N College, Virudhunagar, Tamilnadu, India. \\ *E-mail: smchen78@ms15.hinet.net ; xhliu@mail.njust.edu.cn
}

doi: $10.20964 / 2017.07 .88$

Received: 13 April 2017 / Accepted: 29 May 2017 / Published: 12 June 2017

A simple and effective amperometric sensor based on activated screen printed carbon electrode (ASPCE) was successfully fabricated for the electrochemical determination of resorcinol (RC). The ASPCE was fabricated by electrochemical method and it was characterized by using various numerous technique. The electrocatalytic behaviour of the fabricated ASPCE were examined by the cyclic voltammetry (CV) and amperometric method (I-T). Remarkably, ASPCE exhibited an excellent electrocatalytic activity in terms of decrease the potential and increase the anodic peak current for the detection of RC when compared to bare SPCE. The ASPCE was successfully determined the GA and it showed linear response range from 1 to $49.67 \mu \mathrm{M}$ and the low detection of limit (LOD) of $0.288 \mu \mathrm{M}$. Furthermore, the proposed sensor electrode was revealed an excellent selectivity and good stability. To the best of our knowledge, this fabricated electrode is cost effective and good electrochemical performance towards the determination of $\mathrm{RC}$ when compared with previously reported other chemically modified electrodes.

Keywords: Resorcinol, Cyclic voltammetry, Electrochemistry, Activated screen printed carbon electrode. 
(C) 2017 The Authors. Published by ESG (www.electrochemsci.org). This article is an open access article distributed under the terms and conditions of the Creative Commons Attribution license (http://creativecommons.org/licenses/by/4.0/). 